\title{
Promoting and Marketing Asian Crops
}

Carol A. Miles and D. Gayle Alleman

\begin{tabular}{l} 
ADDITIONAL INDEX WORDS. market criteria, consumer awareness, extension publications \\
\hline SummaRY. Asian crops can provide growers with a means to diversify crop production and \\
marketing options. However, before expanding into Asian crops, growers should determine \\
consumer expectations regarding a new crop. Existing market criteria for each crop (i.e., \\
maturity, color, size, shape) must be considered for all markets including traditional Asian use \\
as well as for the general North American market. If growers decide to target general consum- \\
ers in North America, then consumer awareness and acceptance must be addressed in a \\
marketing and promotion program. Extension publications, popular magazines, and newspa- \\
pers are useful tools in a marketing and promotion program. Crop production information \\
must be available to enable growers to successfully produce Asian crops. Yet, most growers are \\
unlikely to invest heavily in new production equipment and systems until a market has been \\
established for the crop. It is a challenge for university scientists and extension agents to \\
concurrently create supply and demand for new Asian crops. To accomplish this, multidisci- \\
plinary teams that include university and community experts should initiate a diversified \\
program of Asian crop production, promotion, and marketing.
\end{tabular}

sian crops may be marketed for traditional Asian uses, or to
general consumers for inclusion in a typical North American
diet. For example, edamame (Glycine max), also referred to as vegetable soybeans, are traditionally served in Japan as whole pods and are eaten as a snack with beer-similar to the way peanuts and popcorn are consumed in North America. If the target market is for this traditional Asian use, then growers and marketers must consider consumer expectations for this use. For example, Japanese consumers prefer edamame pods that have a light-colored pubescence and that contain two or more beans per pod (Konovsky et al., 1994). If the target market for edamame is for use in a general North American diet, where edamame are marketed as a shelled bean for inclusion in stir-fries, salads, pasta dishes, etc., then pod characteristics are no longer important. This example of a nontraditional use of an Asian crop in North America enables growers to capture a much larger market segment than would be reached by marketing edamame as a snack in Japanese restaurants. 
It will also be necessary to decide if the target market is domestic or for export. To export a North Americangrown Asian crop to Asia, growers and/or marketers may need to work with a food buyer who has well-established marketing networks in Asia. As with many businesses, it is important to build relationships among growers, marketers, and buyers. It may take several years to establish these relationships. If the Asian crop is intended for use domestically, then promotional information must be developed for the North American consumer. The general public will likely be unfamiliar with a new Asian crop and will not know how to select, store, or prepare it. For instance, if a customer were to buy whole edamame pods and attempt to eat the beans and the pods, they would probably never purchase edamame again. Edamame pods are tough and fibrous and are not considered to be edible. To encourage repeat sales, it is critical that specific instructions be included with these new foods. The general public will also be unfamiliar with the nutritional value of a new Asian crop. Our experience shows that growers and consumers are interested in nutrient content in addition to flavor. The rich vitamin, mineral, and phytochemical contents of some Asian crops are additional selling points.

\section{Educating consumers}

Brochures on crop selection, storage, preparation, and nutrient content should be available at the point of sale. Recipe cards that provide instructions on how to use the crop in a variety of ways are an excellent marketing tool. Customers should be encouraged to take these written materials home so that accurate storage and tasty preparation instructions are available when and where the customer needs them. Recipe cards are ideal marketing tools because they are inexpensive to produce and can contain general crop information as well as recipes. Promotional brochures and recipe cards can also provide a good mechanism for promoting local or domestic production if those aspects of production are part of the marketing strategy. For example, brochures developed for several Asian crops at Washington State University included a section entitled Food From the Field (Alleman and Miles, 1999). This section of the brochure encouraged consumers to purchase these Asian crops from local farm businesses, thereby contributing to the economic sustainability of regional farms.

Public events such as farmers markets; harvest celebrations; and town, county, and state fairs, provide good venues for educating the general public and distributing promotional information. To reach potential consumers at these events successfully, an attractive booth and a good-humored staff are essential. Public events are viewed as entertainment, and a booth that contains samples of Asian crops; a cooking demonstration with taste samples; and free seed, recipe cards, and brochures is both attractive and educational. Working such a booth at a public event is much like working a booth at a farmers market; only people who enjoy conversing with the general public and who can remain smiling after hours of repeating the same information will be successful. In Washington State, Master Gardener's typically set up an information table or booth at farmers' markets. Occasionally they offer samples of new crops prepared in a tasty manner and brochures and recipe cards for that food. Often this encourages consumers to shop for the products from growers at the market.

Marketing and promotional activities can go far beyond venues such as farmers' markets and fairs. Articles published in magazines, newspapers, and newsletters are excellent ways to educate consumers about Asian crops. While extension and scientific publications are a good means of reaching colleagues, few consumers read these publications. An article in a national magazine can reach hundreds of thousands of people at no cost to the university program or grower. For instance, general consumers can be reached through food and gardening sections of local, regional, and national newspapers. Garden and food enthusiasts will read garden, health, and epicurean magazines. Restaurant and hotel chefs can be reached through trade publications and epicurean magazines.

When publishing an article about Asian crops in a magazine or newspaper, it is advisable to prepare detailed information about the crop. Post this detailed information on the university Website, and include the Website address in the article. In this way, it is possible to avoid the time and expense otherwise needed to answer a multitude of reader's questions. Citing extension publications and university Websites in magazine and newspaper articles can contribute significantly to increased public awareness of the project and the university as a whole.

\section{Initiating a production and marketing program}

It is difficult to convince growers to produce a new Asian crop for which there is no demand. Yet it is also difficult to create an informed public that wants the product only to find that the product is not yet available. This barrier was overcome in western Washington by encouraging growers to produce test plots under the guidance of the local area agricultural agent. Growers then marketed the crop at farmer's markets along with the point-of-sale brochures and recipe cards. As the growers' crops sold quickly at the markets, they were encouraged to plant more of the crop the following year. To encourage growers to grow Asian crops, it was pointed out to them that these foods, being both unusual and delicious, typically bring a very good price. As the growers realized they were growing a high-value crop for which demand was being created, they were more enthusiastic to be first at the market with a new product.

An added benefit of some Asian crops is that they are a secondary crop for which no additional field space is needed to raise them. For instance, baby corn (Zea maysvar. saccharata) is simply an immature ear of corn that can be harvested from the same plant that is being grown for sweet corn production (Miles and Zenz, 2000). If the primary ear is harvested for sweet corn, the secondary ear can be harvested for baby corn. Similarly, pea shoots (Pisum sativum) are the growing tips of any edible pea vine and are harvested before or concurrently with mature peas (Miles et al., 1999). Thus, additional value is added to existing crops at no additional growing costa boon to any grower.

\section{Promotion}

Developing promotional maTERIALS. It is essential that brochures and recipe cards be attractive, preferably with a sketch or picture of the crop on the front. Typical brochure information includes 
- History and origin of the crop (brief, 3 to 4 sentences)

- How to select for best flavor

- How to safely store/preserve the crop and how long it will remain fresh

- How to prepare and use the crop in everyday meals

- Nutritional and phytochemical content plus health benefits

- At least one recipe

- Paragraph on the importance of supporting local farmers

- Contact for more information, e.g., phone, Websites, e-mail.

Food composition charts are used to help determine nutrient content. Both U.S. and Japanese charts are helpful for vitamin and mineral content, while new databases provide information on certain phytochemicals such as phytoestrogen and carotenoid content (Japanese Science and Technology Corporation, 1996; USDA, 1999a, 1999b). University staff in the human nutrition department or a dietitian can help in interpreting these values and discussing their health value.

\section{Extension publications}

Extension publications, such as production guidelines, newsletters, and Web pages are the backbone of an extension and research program. If the crop has been successfully promoted, growers need production guidelines to meet the new market demand quickly. Therefore, production guidelines should be prepared in advance of a full-fledged marketing campaign. If an article is published in garden or food magazines and newspapers, it is also necessary to provide garden production information.

\section{Asian crops are food}

Perhaps the single greatest factor that will help university scientists to promote Asian crops is the realization that the crops that growers produce are the foods that consumers eat. Consumers do not buy agricultural products; they buy food for taste and health. To market an Asian crop successfully, the crop must be viewed as a food item. Chefs and farmer's market coordinators are valuable partners in promoting Asian crops as food items.
Chefs typically like to provide recipes for recipe card development, especially if the card includes their name and the name of the restaurant with which they are associated. Some chefs feature a specific local crop or a farm on their menus and may even develop seasonal menus with farmers so that farmers can plan crop planting and harvesting schedules. Organizations such as the Chef's Collaborative (Cambridge, Mass.) or state restaurant associations can provide good contacts for establishing linkages with local chefs. At Washington State University, a Chef-Farmer Directory was published to facilitate the formation of these linkages (Cheeke and Miles, 2000). Farmer's market coordinators are generally receptive to programs that promote market attendance and sales. Successful programs at farmers markets may include food workshops and cooking demonstrations that include local chefs, nutritionists, or food writers.

To promote Asian crops as food items, it is helpful to form multidisciplinary teams that include university and community-based food and nutrition specialists. Food, food safety, and nutrition specialists provide health and nutrition information as well as easy-tofollow preparation and storage instructions for brochures, recipe cards, and articles. Food writers from magazines and newspapers can also provide valuable skills to teams and have a keen sense for current public interest topics. To contact food writers in an area, refer to the food and living sections of local and regional newspapers. Additionally, most national newspapers include a weekly section that focuses on food and/or gardening. National newspapers have regional offices throughout North America, and these offices can be reached through the news/media liaison at the university.

\section{Conclusions}

To promote and market Asian crops successfully in North America, it is critical to identify the target market first. If the target market is the North American general public, then consumer awareness and acceptance must be priority items. A multidisciplinary team is useful and should include an agricultural extension agent who recognizes the link between agriculture and food, food safety experts, and pro- fessional chefs and writers. Brochures, recipe cards, and magazine and newspaper articles are excellent ways to reach the general public and to increase consumer awareness-not only of Asian crops but also of the university as a whole. Promote traditional extension publications and Web sites in each of these marketing tools as well as information about the importance of supporting local agriculture. Supply and demand will soon hopefully achieve a balance through these techniques.

\section{Literature cited}

Alleman, G. and C. Miles. 1999. Edamame. Wash. State Univ. Coop. Ext. 5 June 2001. <http://agsyst.wsu.edu/edbroc.htm>.

Cheeke, T., and C. Miles. 2000. 20002001 chef/farmer connection directory: linking Washington chefs to Washington farmers. Wash. State Univ. Coop. Ext. Lewis County Publ. 5 June 2001. <http:/ /agsyst.wsu.edu/cheffarmdir.htm $>$.

Japanese Science and Technology Corporation. 1996. Japanese standard tables of food composition, $4^{\text {th }}$ ed. 5 June 2001. <http://food.tokyo.jst.go.jp/ index.html $>$.

Konovsky, J., T.A. Lumpkin, and D. McClary. 1994. Edamame: the vegetable soybean, p. 173-181. In: A.D. O'Rourke (ed.). Understanding the Japanese food and agrimarket: a multifaceted opportunity. Haworth Press, Binghamton.

Miles, C.A. and L. Zenz. 2000. Baby corn. Wash. State Univ. Coop. Ext. Publ. PNW 0532. 5 June 2001. <http:// cru.cahe.wsu.edu/CEPublications/ pnw0532/pnw0532.pdf>.

Miles, C. A., R. Nakatani, and M. Musick. 1999. Pea vine production and marketing study. Wash. State Univ. Coop. Ext. Lewis County Publ. 5 June 2001. <http:// agsyst.wsu.edu/peareport.htm>.

U.S. Department of Agriculture-Agricultural Research Service. 1999a. USDA nutrient database for standard reference. Release 13. Nutrient Data Laboratory Home Page. 5 June 2001 . "http:// www.nal.usda.gov/fnic/foodcomp" http://www.nal.usda.gov/fnic/ foodcomp $>$.

U.S. Department of Agriculture-Agricultural Research Service. 1999b. USDAIowa State Univ. database on the isoflavone content of foods. Release 1.2.5 June 2001. <http://www.nal.usda.gov/fnic/ foodcomp/Data/isoflav/isoflav.html>. 